\title{
Desain Prototipe Meja dan Kursi Pantai Portabel dengan Integrasi Pendekatan Ergonomi, Value Engineering dan Kansei Engineering
}

\author{
Nora Yuanita Restantin ${ }^{1}$, Mirwan Ushada $^{1^{*}}$, Makhmudun Ainuri $^{1}$
}

\begin{abstract}
This research highlighted a methodology to design prototype of portable dining table and chairs for the beach by the integration of Ergonomic, Value Engineering and Kansei Engineering. The case study of the research is on Kuwaru Beach. It has its special features compared to other beach that is an open green space which is filled with pine trees shrimp. The location is become a visitors favorite place in enjoying the beauty of sea and the culinary feature. However sand is exposed to sea breeze could contaminate food. While visitors "lesehan seating" position makes visitors easily get exhausted. This gives an altenative that provides dining facilities to support the outdoor atmosphere with the type rather than "lesehan" based on ergonomic approach and Value Engineering. Research using the concept of Kansei Engineering aims to get the design of portable dining table and chairs which comfortable and practical by developing product based on the imagination consumers. Research result indicated the best performance is obtained by the prototype concept I which have a total cost of Rp 500000.00 and a value based visitors $66.20 \times 10^{-5}$ and restaurant owner $71.19 \times 10^{-5}$.
\end{abstract}

Keywords: Portable dining tables and chairs, ergonomic, Kansei engineering, value engineering

\section{Pendahuluan}

Pengembangan meja kursi pantai portabel untuk rekreasi merupakan kebutuhan untuk kenyamanan pengunjung yang berdampak terhadap meningkatnya jumlah pengunjung. Wisata tujuan khusus rekreasi memerlukan tinjauan terintegrasi dari segi ergonomi, nilai dan perasaan psikologis konsumen dalam mengembangkan produk. Salah satu pantai yang ada di Daerah Istimewa Yogyakarta adalah Pantai Kuwaru. Pantai Kuwaru memiliki daya tarik tersendiri dibandingkan dengan pantai-pantai lain, yaitu terdapat ruang terbuka hijau yang dipenuhi dengan pohon cemara udang. Lokasi tersebut menjadi tempat favorit pengunjung dalam menikmati keindahan laut dan kuliner laut namun pasir yang terkena hembusan angin laut dikhawatirkan dapat mengkontaminasi makanan. Sedangkan posisi duduk pengunjung yang lesehan membuat pengunjung cepat mengalami kelelahan. Hal ini memberikan alternatif, yakni menyediakan fasilitas tempat makan yang mendukung suasana outdoor dengan tipe bukan lesehan. Meja kursi portabel yang dijual dipasaran dibuat berdasarkan fungsi umum dan belum mengakomodasi anthropometri pengunjung pantai dan atribut keunikan alam pantai.

\footnotetext{
1, Fakultas Teknologi Pertanian, Jurusan Teknologi Industri Pertanian, Universitas Gadjah Mada, Jl. Flora 1, Bulaksumur, Yogyakarta 55281, Indonesia.

Email: mirwan@tip-ugm.org

* Penulis korespondensi
}

Penggunaan pendekatan terpadu Ergonomi, Value Engineering dan Kansei Engineering diperlukan untuk menghasilkan produk yang memenuhi kebutuhan konsumen.

Penelitian ini bertujuan untuk mendapatkan desain dan prototipe meja dan kursi makan portabel yang nyaman serta praktis bagi pengunjung dan pemilik rumah makan dengan integrasi pendekatan Ergonomi, Value Engineering dan Kansei Engineering. Kontribusi penelitian ini adalah untuk membantu pemerintah Kabupaten Bantul dalam pengembangan kawasan wisata Pantai Kuwaru. Nagamachi [8] menyatakan Kansei Engineering sebagai metode pengolah nilai dan Kansei sebagai input menjadi atribut produk sebagai output. Pengembangan Kansei Engineering ini merupakan teknologi ergonomi berorientasi konsumen yang digunakan untuk menerjemahkan perasaan konsumen sebagai dasar pengembangan produk baru.

Nilai Kansei adalah imajinasi konsumen terhadap produk/ layanan. Ushada dan Murase [19] telah mengadaptasi Kansei Engineering dalam pengembangan produk greening material berdasarkan tingkat kepentingan atribut produk. Kansei Engineering telah diterapkan dalam berbagai desain produk. Cakupan lain dalam pengembangan kansei telah diterapkan dalam desain peralatan rumah tangga, arsitektur, desain pengemasan dan peralatan kerja. Telah dilakukan studi pada penyelesaian tingkat permukaan mikro dengan material kaca (Barnes et $a l$. [2]) dan genre musik untuk iklan ponsel (Deng 
dan Kao [3]) serta Greening Material untuk Kawasan Merapi (Ushada et al. [20]).

Value Engineering adalah suatu penerapan yang sistematis dari sejumlah teknik untuk mengidentifikasi fungsi-fungsi suatu produk baru dengan memberi nilai terhadap masing-masing fungsi yang ada serta mengembangkan sejumlah alternatif yang memungkinkan tercapainya fungsi tersebut dengan biaya total minimum tanpa mengurangi penampilannya (Ulrich dan Eppinger [18]).

Hasil akhir dari analisis ergonomi akan menghasilkan desain yang memberikan kenyamanan secara anthropometri kepada pengguna meja kursi tersebut. Aplikasi ergonomi dalam proses perencanaan produk, biasanya memiliki peran yang sangat penting, sehingga aspek ini dikategorikan mempunyai skala prioritas tinggi (Palgunadi [11])

\section{Metode Penelitian}

Penelitian dilakukan di Kawasan Pantai Kuwaru, Kabupaten Bantul Provinsi DIY pada bulan JuniOktober 2011. Responden yang digunakan sebagai objek penelitian adalah pengunjung yang sedang duduk lesehan di kawasan cemara udang dan pemilik rumah makan yang berada di pinggir pantai dekat kawasan cemara udang. Kuesioner dibagi menjadi dua bagian untuk pengunjung, yakni kuesioner pengukuran kenyamanan dan kuesioner ergonomi menggunakan Nordic Body Map. Kuesioner kenyamanan untuk mendapatkan Kansei Words dalam Kansei Engineering. Martadi [7] menjelaskan bahwa meja dan kursi yang ada dipasaran bersifat general dan untuk keperluan khusus seperti bangku dan kursi sekolah dasar harus didesain secara khusus. Tentu saja, meja dan kursi pantai portabel ini juga perlu didesain secara khusus.

Faktor yang diteliti dari pengunjung berupa tingkat kenyamanan dan kelelahan (kesakitan) saat pengunjung duduk lesehan di tepi Pantai Kuwaru, terutama kawasan pohon cemara udang. Pada pemilik berupa atribut kebutuhan dalam perancangan. Kemudian berdasarkan pertimbangan tersebut diteliti tanggapan pemilik dan pengunjung terhadap prototipe produk meja dan kursi makan portabel yang dihasilkan.

Metode rancang bangun ini menggunakan value engineering yang dibantu dengan Kansei Words dalam Kansei Engineering untuk mengetahui atribut kenyamanan pengunjung saat berwisata. Tingkat keluhan pengunjung di bagian tubuh saat duduk lesehan yang dinilai berdasarkan Nordic Body Map Questionnaire menjadi dasar pertimbangan bagi rancangan meja dan kursi makan yang ergonomis.

\section{Prosedur Kansei Engineering}

Prosedur standar pendekatan Kansei Engineering terdiri dari empat langkah (Nagamachi [8, 9]); (1) Identifikasi kebutuhan konsumen akan produk dari segi ergonomis dan images produk berdasarkan perasaan psikologis (2) Ekstraksi parameter produk yang dapat memuaskan calon konsumen. (3) Mengembangkan Kansei Engineering sebagai teknologi ergonomis (4) Penyesuaian desain produk berdasarkan preferensi konsumen dan kelompok sosial. Penggunaan konsep Kansei Engineering ini dengan memperoleh informasi dari fungsi rekreasi dan ergonomi. Pengidentifikasian atribut kebutuhan konsumen dalam Value Engineering menggunakan pendekatan Kansei Engineering. Pada tahapan ini diharapkan dapat memahami dan mengerti perasaan konsumen (Kansei) terhadap produk dalam istilah ergonomi dan psikologi. Skala yang digunakan dalam pengukuran adalah skala likert (Ushada dan Murase [19]) karena skala ini di gunakan untuk pengukuran metode Kansei Engineering melengkapi pola penggunaan semantik bipolar.

\section{Prosedur Ergonomi}

Penerapan ergonomi umumnya merupakan aktivitas rancang bangun (desain) ataupun rancang ulang (Nurmianto [10]). Anthropometri menurut Stevenson [14] dan Nurmianto [10] adalah satu kumpulan data numerik yang berhubungan dengan karakteristik fisik tubuh manusia ukuran, bentuk dan kekuatan serta penerapan dari data tersebut untuk penanganan masalah desain.

Pengunjung akan diukur tingkat keluhan rasa nyeri pada bagian tubuh yang ditunjukkan oleh gambar peta tubuh, sehingga memudahkan untuk mengidentifikasi letak rasa nyeri tersebut. Kuesioner ini nantinya untuk menentukan kebutuhan konsumen berdasarkan faktor ergonomi. Instrumen Nordic Body Map yang terdiri dari 27 items pertanyaan sudah biasa digunakan terutama untuk penelitian ergonomi (Suwarno [16]). Melalui Nordic Body Map dapat diketahui bagian-bagian otot yang mengalami keluhan dengan tingkat keluhan mulai dari rasa tidak nyaman (agak sakit) sampai sangat sakit (Tarwaka et al. [17]).

Penerapan data anthropometri ini akan dapat dilakukan jika tersedia mean (rata-rata) dan SD (Standard Deviation) dari distribusi normal. Penentuan dimensi ukuran yang akan menggunakan data antropometri, maka harga rata-rata (mean) dari ukuran bagian anggota tubuh (tinggi badan, panjang lengan dan sebagainya) merupakan data terpenting yang harus diketahui dan diukur. 


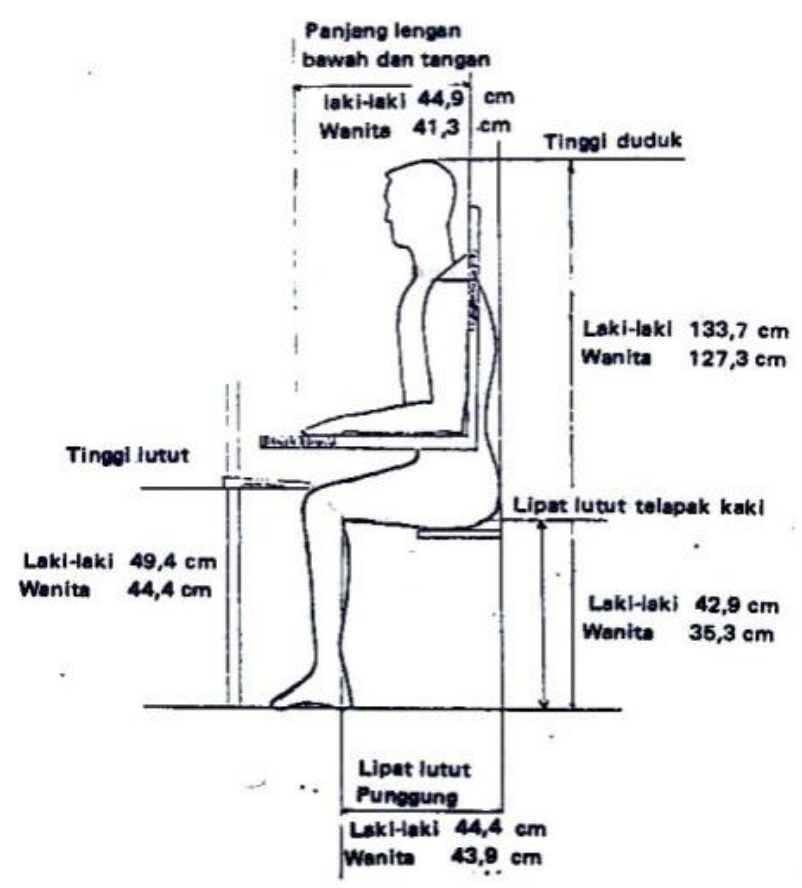

Sumber: Suma'mur [15]

Gambar 1. Ukuran-ukuran penting pada sikap duduk

Meskipun banyak karakteristik antropometri yang tidak bisa semuanya digambarkan secara persis memenuhi persyaratan distribusi normal, tetapi dengan pendekatan distribusi normal ini dengan mudah akan bisa ditetapkan bahwa harga rata rata dari sebuah obyek pengukuran akan ekivalen dengan ukuran Persentil 50. Dengan demikian variabilitas dari ukuran fisik manusia yang ada dalam populasi akan bisa dijelaskan melalui perhitungan statistik dengan memakai parameter harga rata-rata, standard deviasi atau koefisien variasi yang ada (Wignjosubroto [22]).

Data anthropometri yang digunakan untuk memenuhi analisis ergonomi, sehingga perancangan yang dihasilkan dapat menyesuaikan suasana lingkungan dengan aktivitas pengunjung. Ergonomi sendiri digunakan sebagai dasar pengukuran anthropometri terhadap fungsi-fungsi tubuh manusia, kaitannya dengan lingkungan agar tercapainya kenyamanan fungsional suatu sarana. Pedoman dalam mendesain mebel ini menggunakan data anthropometri yang berkaitan pengukuran tubuh manusia secara fisik. Anthropometri meliputi pengukuran pada sikap berdiri (tinggi badan posisi tegak), tinggi badan posisi duduk, jarak dari lipat lutut (polipteal) ke pantat, tinggi lipat lutut, tinggi siku pada posisi duduk, tinggi lutut (Gambar 1).

Data anthropometri tinggi badan posisi duduk untuk mengantisipasi agar saat pengunjung duduk di meja dan kursi makan portabel tidak mengenai pohon cemara udang. Jarak lipat lutut ke pantat dan lebar panggul berfungsi menentukan panjang dan lebar alas duduk. Sedangkan tinggi lipat lutut untuk mengetahui tinggi dari kursi. Tinggi meja diperoleh dari tinggi lipat lutut dan tinggi siku pada saat duduk. Persentil 95 digunakan pada perhitungan anthropometri lebar panggul dan tinggi badan posisi duduk, persentil lainnya menggunakan persentil 50. Persentil 95 digunakan dengan tujuan agar $95 \%$ populasi dapat menggunakannya dengan nyaman.

\section{Prosedur Value Engineering}

Tahapan yang dilakukan dalam penelitian ini terdiri dari tiga tahapan yakni tahap informasi dengan mengumpulkan informasi yang diperlukan dari pengunjung dan pemilik rumah makan. Pada tahap pengembangan dan kreativitas dilakukan pemetaan fungsi atribut, penyusunan konsep dan pembuatan prototipe. Kemudian pada tahap analisis dilakukan evaluasi produk untuk mengetahui nilai performansi produk dan penentuan value produk sehingga didapatkan konsep akhir produk.

\section{Konsep Desain}

Desain yang berpusat pada manusia adalah untuk mengintegrasikan teknologi dan sumber daya lainnya (Rouse [12]). Menurut Madyana [6], desain adalah kegiatan pemecahan masalah atau inovasi teknologis yang bertujuan untuk mencari solusi terbaik (sistem, proses, konfigurasi fisikal) dengan jalan memformulasikan terlebih dahulu gagasan inovatif tersebut ke dalam suatu model dan kemudian merealisasikan kenyataan secara kreatif.

Integrasi ergonomi, Value Engineering dan Kansei Engineering dalam penelitian ini dapat dijabarkan dalam Gambar 2.

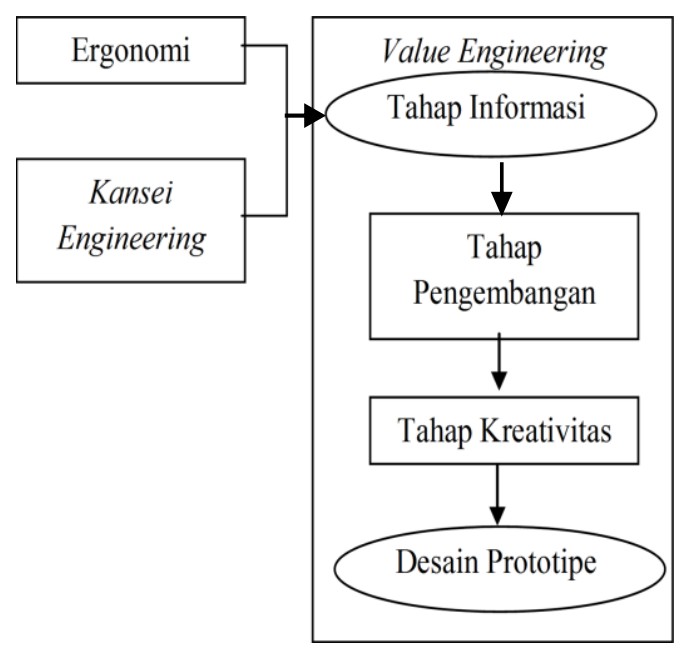

Gambar 2. Diagram pengintegrasi metode 


\section{Hasil dan Pembahasan}

\section{Tahap Informasi}

Kuesioner pendahuluan berisi atribut-atribut pengukuran kenyamanan saat berada di lingkungan wisata dan merupakan kata-kata mentah (Kansei Words) yang diperoleh dari hasil wawancara seperti "Nyaman" dan "Tidak Pegal". Penyebaran kuesioner utama dilakukan secara purposive sampling kepada 120 responden pengunjung dan 10 pemilik rumah makan. Kuesioner kenyamanan untuk pengunjung terdiri dari 5 atribut primer (fasilitas, lingkungan, estetika, aktivitas, kekhasan flora dan fauna) dan 12 atribut sekunder (memadai, nyaman, bersih, sejuk asri, nikmat dipandang, menarik, keindahan, tempat bermain, berolahraga, wisata, penyu, pohon cemara udang). Atribut kekhasan flora fauna diadaptasi dari Fandeli [4] tentang kepariwisataan alam. Kemudian pengukuran ergonomi dengan kuesioner Nordic Body Map terdiri dari 27 item pertanyaan. Pada kuesioner pendahuluan pemilik rumah makan terdiri dari 5 atribut primer (kualitas, bentuk, kerapian, kepraktisan, kemudahan perawatan dan pembersihan) dan 10 atribut sekunder (kekuatan dan keawetan, tahan pada kondisi cuaca pantai, banyak variasi, kesan kokoh, permukaan tidak kasar, sudut-sudut telah dihaluskan, kemudahan memindah dan mudah dibersihkan). Atribut yang tidak valid adalah model yang unik dan tambahan ornament karena pengunjung berorientasi pada kepraktisan dan aspek fungsional produk. Pengujian validitas dilakukan terhadap butir-butir kuesioner tersebut untuk mengetahui tingkat kepentingan dari pengunjung dan pemilik rumah makan. Uji dilakukan dengan menghitung korelasi masing-masing pernyataan dengan skor total menggunakan rumus korelasi product moment. Suatu pertanyaan dikatakan valid dan mampu mewakili tujuan penyebaran kuesioner apabila memiliki nilai $R_{\text {hitung }}>$ nilai $R_{\text {tabel. }}$. Pengujian reliabilitas dilakukan terhadap butir pernyataan yang valid menggunakan Alpha Cronbach (Arikunto [1]). Suatu butir pertanyaan dinyatakan reliabel atau konstan dalam pengambilan datanya apabila memiliki nilai $R_{\text {hitung }}>$ nilai $R_{\text {tabel }}$ Tabel uji validitas dan reliabilitas kenyamanan pengunjung ditunjukkan pada Tabel 1 dan Tabel 3 uji validitas dan reliabilitas kuesioner ergonomi. Pada Tabel 2 menunjukkan uji validitas dan reliabilitas untuk pemilik rumah makan.

Hasil rekapitulasi menunjukkan Nordic Body Map Questionnaire menunjukkan tingkat keluhan terbesar ada di bagian pantat (6,78\%), Sakit di punggung bawah (6,64\%), Sakit di pinggang, kaki kiri dan kanan $(5,60 \%)$, pergelangan kaki kanan (5,31\%), betis kanan (5,16\%), lutut kiri dan betis kanan (5,01\%), paha kanan dan pergelangan kaki kiri (4,72\%) (Gambar 3).
Tabel 1. Uji validitas dan reliabilitas kenyamanan pengunjung

\begin{tabular}{|c|c|c|c|c|}
\hline Butir & Atribut & & Validitas & Reliabilitas \\
\hline 1 & Fasilitas & Memadai & Valid & Reliabel \\
\hline 2 & & Nyaman & Valid & Reliabel \\
\hline 3 & & Bersih & Valid & Reliabel \\
\hline 4 & Lingkungan & Sejuk Asri & Valid & Reliabel \\
\hline 5 & & $\begin{array}{l}\text { Nikmat } \\
\text { dipandang }\end{array}$ & Valid & Reliabel \\
\hline 6 & & Menarik & Valid & Reliabel \\
\hline 7 & Estetika & Keindahan & Valid & Reliabel \\
\hline 8 & Aktivitas & $\begin{array}{l}\text { Tempat } \\
\text { Bermain }\end{array}$ & Valid & Reliabel \\
\hline 9 & & Olahraga & Tidak Valid & \\
\hline 10 & & Wisata & Valid & Reliabel \\
\hline 11 & $\begin{array}{l}\text { Kekhasan } \\
\text { Flora } \\
\text { dan Fauna }\end{array}$ & Penyu & Valid & Reliabel \\
\hline 12 & & $\begin{array}{l}\text { Pohon } \\
\text { Cemara } \\
\text { Udang }\end{array}$ & Valid & Reliabel \\
\hline
\end{tabular}

Tabel 2. Uji validitas dan reliabilitas pemilik rumah makan

\begin{tabular}{|c|c|c|c|}
\hline Butir & Atribut & Validitas & Reliabilitas \\
\hline 1 & Kekuatan dan Keawetan & Valid & Reliabel \\
\hline 2 & $\begin{array}{l}\text { Tahan pada kondisi } \\
\text { cuaca pantai }\end{array}$ & Valid & Reliabel \\
\hline 3 & Model yang unik & Tidak Valid & - \\
\hline 4 & Banyak variasi & Valid & Reliabel \\
\hline 5 & Kesan kokoh & Valid & Reliabel \\
\hline 6 & Tambahan ornamen & Tidak Valid & - \\
\hline 7 & Permukaan tidak kasar & Valid & Reliabel \\
\hline 8 & $\begin{array}{l}\text { Sudut-sudut telah } \\
\text { dihaluskan }\end{array}$ & Valid & Reliabel \\
\hline 9 & Kemudahan memindah & Valid & Reliabel \\
\hline 10 & Mudah dibersihkan & Valid & Reliabel \\
\hline
\end{tabular}

Dari penyebaran kuesioner ke pengunjung atribut desain yang diperoleh dari atribut kenyamanan, yang tertinggi ada pada lingkungan, kepraktisan, tampilan desain, kenyamanan, kualitas. Sedangkan pada pemilik atribut tertinngi ada pada kualitas dan diikuti oleh kenyamanan, kepraktisan, bentuk dan kebersihan dan pemilik

\section{Tahap Kreativitas dan Pengembangan}

Suatu konsep produk merupakan deskripsi tentang bentuk, fungsi dan fungsi tambahan yang ada pada produk (features). Penyusunan ini dilakukan dengan mengkombinasikan alternatif pengembangan. Pada Gambar 4 dan Gambar 5 dapat dilihat Kansei Words pengembangan meja dan kursi makan portabel yang dikumpulkan untuk mengidentifikasi atribut kebutuhan dalam pengembangan produk. Kansei Words ini merupakan kunci dari pengembangan karena mencakup nilai kansei yang diperoleh pada tahap awal. Kansei words ini diterjemahkan dari kuesioner menggunakan Diagram Alir Pengidentifi kasian Kebutuhan Konsumen Berdasarkan Kansei Words (Ushada et al., [21] dan Sari et al. [13]). 
Tabel 3. Hasil uji validitas Nordic Body Map Questionnaire

\begin{tabular}{|c|c|c|c|}
\hline No & Lokasi & Validitas & Reliabilitas \\
\hline 0 & Sakit di leher atas & Tidak Valid & \\
\hline 1 & Sakit di leher bawah & Valid & Reliabel \\
\hline 2 & Sakit di bahu kiri & Valid & Reliabel \\
\hline 3 & Sakit di bahu kanan & Valid & Reliabel \\
\hline 4 & Sakit di lengan kiri atas & Valid & Reliabel \\
\hline 5 & Sakit di Punggung & Valid & Reliabel \\
\hline 6 & Sakit di lengan kanan atas & Valid & Reliabel \\
\hline 7 & Sakit di pinggang & Valid & Reliabel \\
\hline 8 & Sakit di punggung bawah & Valid & Reliabel \\
\hline 9 & Sakit di pantat & Valid & Reliabel \\
\hline 10 & Sakit di siku kiri tangan & Valid & Reliabel \\
\hline 11 & Sakit di siku kanan tangan & Valid & Reliabel \\
\hline 12 & Sakit di lengan kiri bawah & Valid & Reliabel \\
\hline 13 & sakit di lengan kanan bawah & Valid & Reliabel \\
\hline 14 & $\begin{array}{l}\text { Sakit di pergelangan tangan } \\
\text { kiri }\end{array}$ & Valid & Reliabel \\
\hline 15 & $\begin{array}{l}\text { Sakit di pergelangan tangan } \\
\text { kanan }\end{array}$ & Valid & Reliabel \\
\hline 16 & Sakit di tangan kiri & Valid & Reliabel \\
\hline 17 & Sakit di tangan kanan & Valid & Reliabel \\
\hline 18 & Sakit di paha kiri & Valid & Reliabel \\
\hline 19 & Sakit di paha kanan & Valid & Reliabel \\
\hline 20 & Sakit di lutut kiri & Valid & Reliabel \\
\hline 21 & Sakit di lutut kanan & Valid & Reliabel \\
\hline 22 & Sakit di betis kiri & Valid & Reliabel \\
\hline 23 & Sakit di betis kanan & Valid & Reliabel \\
\hline 24 & $\begin{array}{l}\text { Sakit di pergelangan kaki } \\
\text { kiri }\end{array}$ & Valid & Reliabel \\
\hline 25 & $\begin{array}{l}\text { Sakit di pergelangan kaki } \\
\text { kanan }\end{array}$ & Valid & Reliabel \\
\hline 26 & Sakit di kaki kiri & Valid & Reliabel \\
\hline 27 & Sakit di kaki kanan & Valid & Reliabel \\
\hline
\end{tabular}

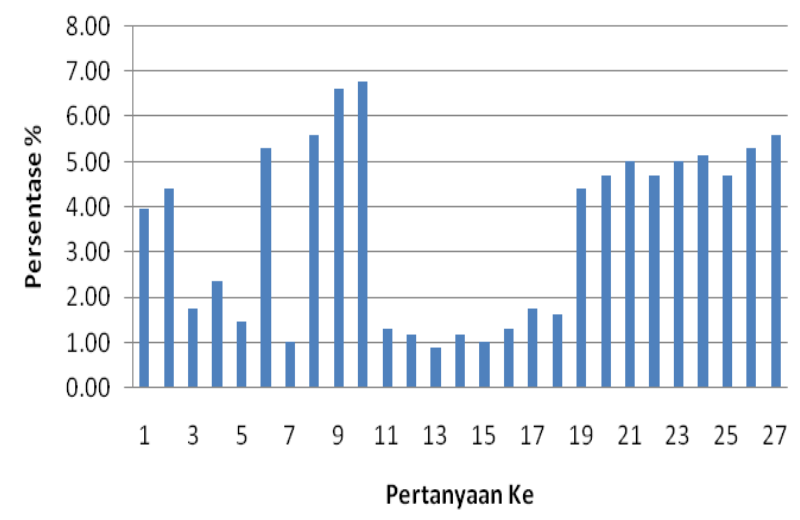

Gambar 3 Persentase rasa sakit yang dirasakan pada bagian tubuh pengunjung

Anthropometri meliputi pengukuran pada sikap berdiri (tinggi badan posisi tegak), tinggi badan posisi duduk, jarak dari lipat lutut (polipteal) ke pantat, tinggi lipat lutut, tinggi siku pada posisi duduk, tinggi lutut. Rata-rata tinggi badan hasil perhitungan yaitu 160,25 cm dengan $\pm 1 \mathrm{~cm}$. Penggunaan data anthropometri tinggi badan pengunjung yang didapatkan ini, dapat digunakan untuk mengetahui data anthropometri yang dibutuhkan lainnya.
Tabel 4. Data anthropometri

\begin{tabular}{|c|c|c|c|}
\hline Data anthropometri & $50 \%$ & SD & $95 \%$ \\
\hline 1 Tinggi badan posisi tegak & 160,16 & 0,45 & 160,90 \\
\hline 6 Tinggi badan posisi duduk & 82,56 & 2,09 & 85,98 \\
\hline $\begin{array}{l}12 \text { Jarak dari lipat lutut (polipteal) } \\
\text { ke pantat }\end{array}$ & 44,40 & 5,05 & 52,68 \\
\hline 14 Tinggi lipat lutut & 40,93 & 1,54 & 43,45 \\
\hline 15 Lebar bahu(bideltoid) & 40,00 & 2,38 & 43,90 \\
\hline 16 Lebar Panggul & 33,43 & 5,13 & 41,84 \\
\hline 9 Tinggi siku pada posisi duduk & 24,83 & 4,21 & 31,73 \\
\hline 13 Tinggi lutut & 49,60 & 1,72 & 52,42 \\
\hline $\begin{array}{l}\text { Tinggi meja (Tinggi lipat lutut + } \\
\text { Tinggi siku saat duduk) }\end{array}$ & 65.76 & 5.40 & 66.99 \\
\hline
\end{tabular}

Tinggi badan yang diperoleh tersebut dikonversikan dengan data anthropometri hasil praktikum Teknik dan Tata Cara Kerja mahasiswa Teknologi Industri Pertanian angkatan 2007 dalam Tabel 4. Hal tersebut karena responden pengunjung diasumsikan normal dan data anthropometri pengunjung dapat dijustifikasi dari data anthropometri mahasiswa. Usia responden yang digunakan sama dengan konsumen restoran pantai. Asumsi tersebut tidak menggunakan data sekunder anthopometri orang Indonesia karena hasil praktikum merupakan data primer yang didapat langsung dari pengukuran.

Berdasarkan data anthropometri yang diperoleh dari rata-rata tinggi badan pengunjung. Pada konsep I memiliki ukuran $110 \times 60 \times 70 \mathrm{~cm}$. Luas permukaaan meja $60 \times 52 \mathrm{~cm}$ untuk mengakomodasi lebar bahu pengguna, tinggi meja $70 \mathrm{~cm}$ dengan luas permukaan alas duduk $60 \times 44 \mathrm{~cm}$ dan tinggi alas permukaan kursi $41 \mathrm{~cm}$. Panjang kursi dari kaki depan hingga belakang $110 \mathrm{~cm}$. Konsep II memiliki ukuran $160 \times 60 \times 70 \mathrm{~cm}$. Luas permukaaan meja $65 \times 60 \mathrm{~cm}$, tinggi meja $70 \mathrm{~cm}$ dengan luas permukaan alas duduk $60 \mathrm{~cm}$ dan tinggi alas permukaan kursi $41 \mathrm{~cm}$. Anthropometri tinggi badan posisi tegak menggunakan persentil 95 adalah 160,90. Tinggi rata-rata pohon cemara udang adalah $180 \mathrm{~cm}$ sehingga tidak mengganggu pengunjung saat beraktivitas dan menggunakan meja dan kursi makan portabel di kawasan tersebut. Lebar bahu berhubungan dengan luas permukaan meja ini merupakan penyesuaian dari luas permukaan alas duduk yang didesain untuk memenuhi ergonomi namun portabel. Gambar konsep meja dan kursi makan portabel dapat dilihat pada Gambar 6(a) dan Gambar 6(b). kemudian dibuat dalam bentuk prototipe fisik ditunjukkan pada Gambar 7(a) dan (b). Kuesioner disebar kepada responden berdasarkan uji coba langsung penggunaan alternatif prototipe.

Keunikan meja kursi ini adalah bentuk modular yang mempermudah dalam sistem produksi mass customization. 


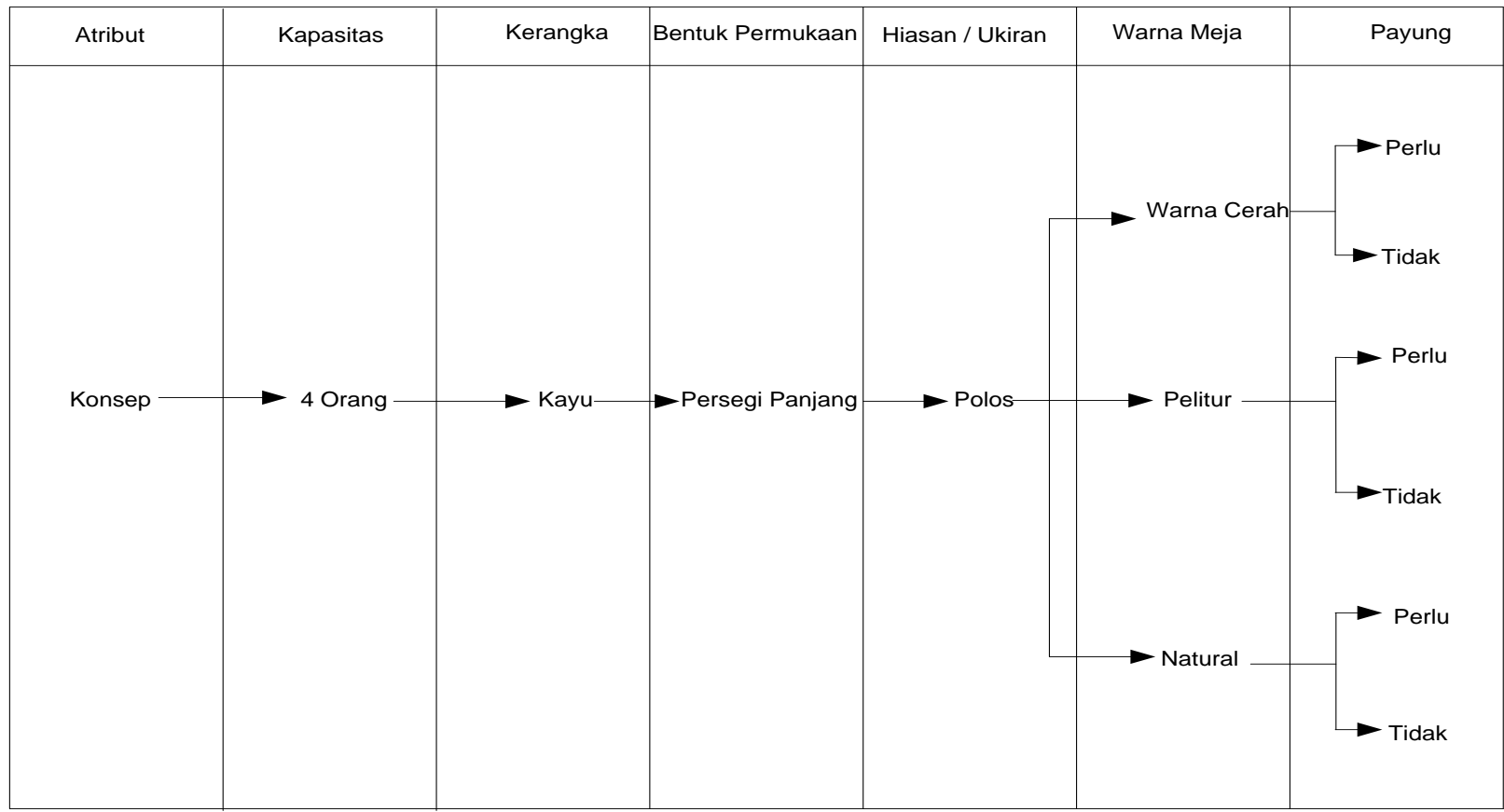

Gambar 4. Diagram Zero Level Concept untuk meja(Adaptasi dari Nagamachi [9])

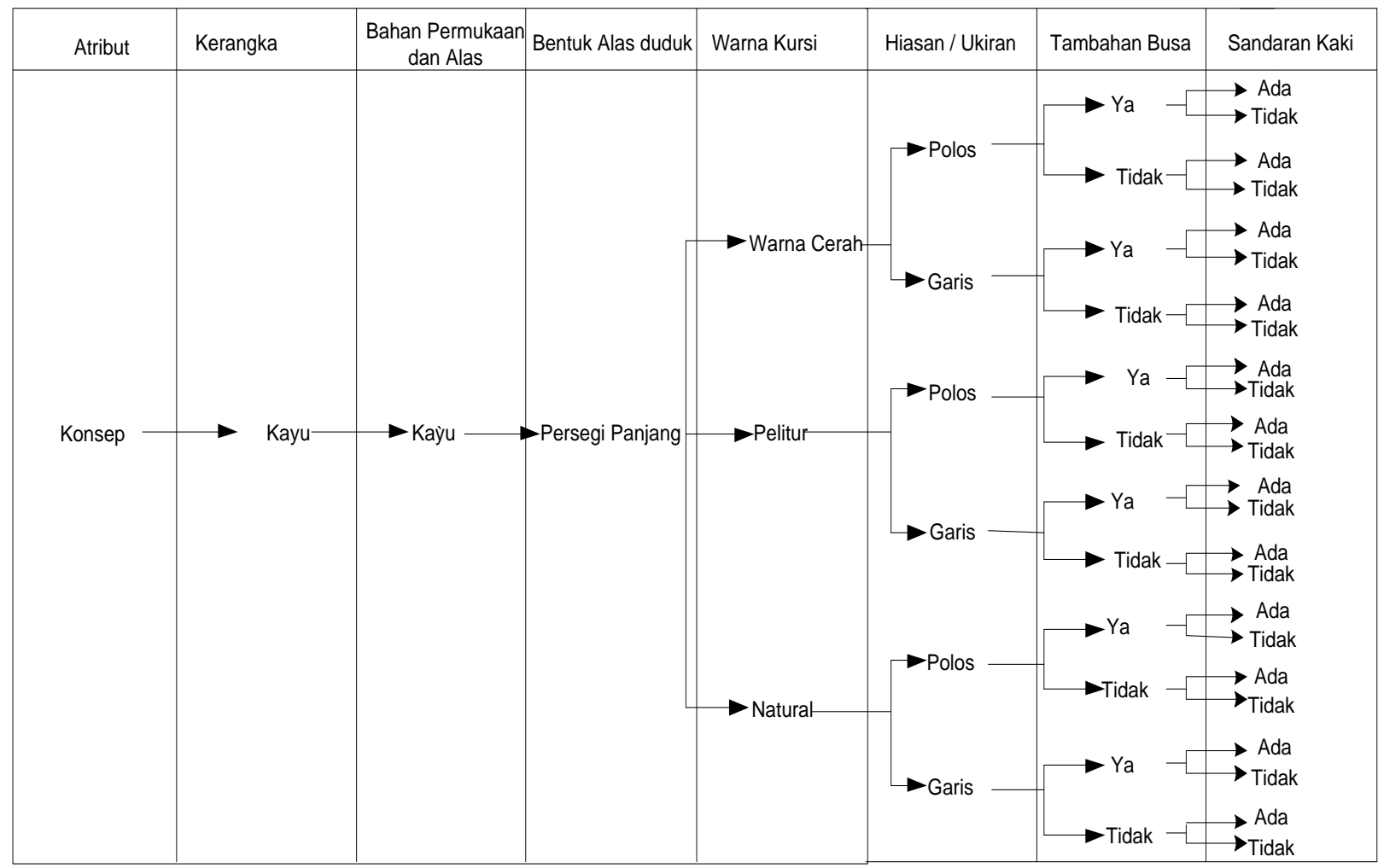

Gambar 5. Diagram Zero Level Concept untuk kursi (Adaptasi dari Nagamachi [9])

Konsep bentuk yang digunakan dalam perancangan meja dan kursi makan portabel ini menggunakan konsep combination/modular dan folding sehingga dapat memudahkan penataan dan menyesuaikan kebutuhan. Konsep modular yang digunakan pada konsep satu dan dua memiliki lipatan yang berbeda.
Materi yang digunakan bersifat ringan dan memenuhi kriteria portabel (Galt Furniture [5]). Desain meja kursi dilakukan berdasarkan konsep modular tersebut. Konsep 1 menunjukkan konsep kursi untuk 1 orang pelanggan dan Konsep 2 menunjukkan konsep untuk 2 orang pelanggan. 


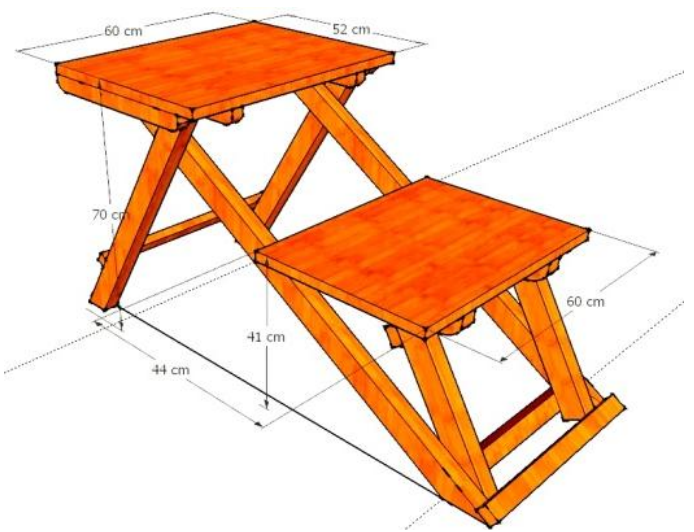

Gambar 6 (a)

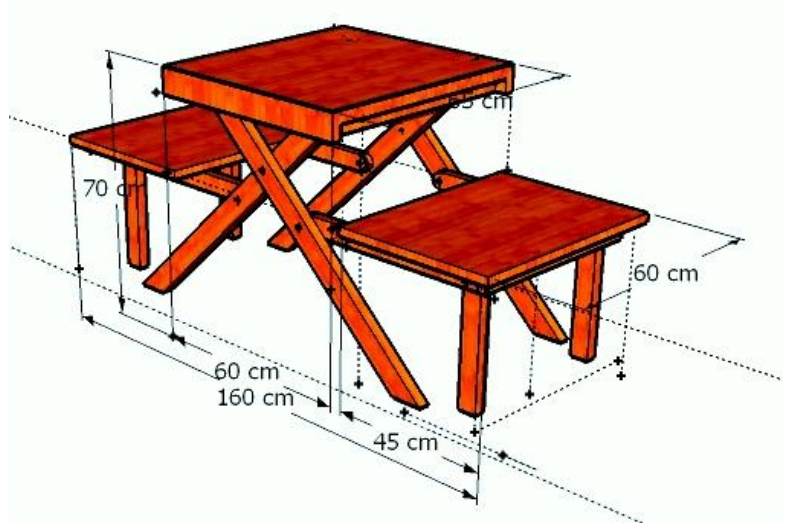

Gambar 6 (b)

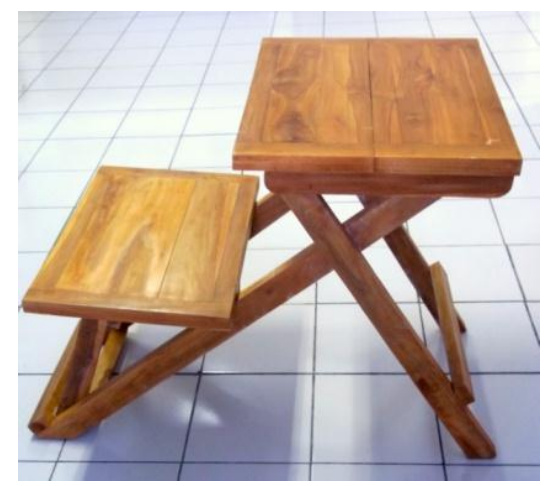

Gambar 7 (a)

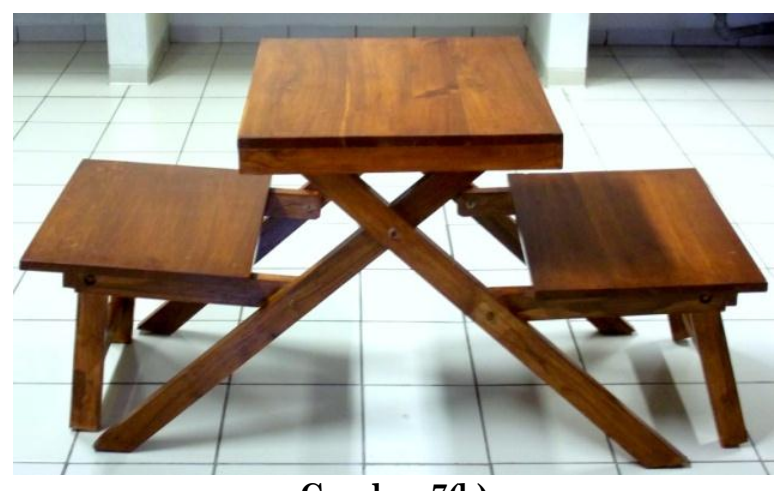

Gambar 7(b)

Gambar 6(a) Prototipe Fisik Meja dan Kursi Makan Portabel Konsep I

Gambar 7(b) Prototipe Fisik Meja dan Kursi Makan Portabel Konsep II

\section{Tahap Analisis}

Total nilai prototipe konsep I dan II penilaian pengunjung sebesar 741 dan 761 (Jumlah responden $=120$ orang). Pada pemilik 178 dan 166 (Jumlah responden $=20$ orang). Total nilai merupakan hasil pengujian dengan menggunakan atribut tampilan desain, kepraktisan, kualitas, kenyamanan dan kebersihan. Pada analisis nilai performansi produk (pengunjung) menggunakan matriks evaluasi total bobot atribut untuk prototipe konsep I ini 65,28 dan Konsep II 34,71. Sedangkan pada penilaian pemilik total bobot untuk prototipe konsep I ini 85,33 dan konsep II 14,67. Diperoleh nilai faktor dari hasil bagi antara total bobot dengan jumlah responden dapat dilihat pada Tabel 5 .

Performansi dihitung dari nilai faktor yang dikali dengan bobot faktor. Nilai dari konsep ditentukan dengan performansi dibagi dengan biaya.

Biaya pembuatan Konsep I adalah sebesar $\mathrm{Rp}$ 700.000,00 dan Konsep II Rp 500.000,00 untuk memperoleh value. Biaya konsep II lebih murah dari konsep I dikarenakan jenis kayu yang digunakan. Dapat dilihat pada Tabel 6.

Berdasarkan Tabel 5 Kedua value menunjukan baik untuk pengunjung atau pemilik rumah makan memiliki nilai yang lebih tinggi pada prototipe konsep I. Perbedaan nilai diantara kedua konsep tidak terlalu jauh. Hal tersebut karena kedua konsep yang modular sehingga tidak terdapat perbedaan nilai yang tinggi

Tabel 5. Nilai faktor prototipe konsep I dan II

\begin{tabular}{lcccc}
\hline \multirow{2}{*}{ Atribut } & \multicolumn{2}{c}{$\begin{array}{c}\text { Pengunjung } \\
\text { total skor }\end{array}$} & \multicolumn{2}{c}{$\begin{array}{c}\text { Pemilik } \\
\text { total skor }\end{array}$} \\
\cline { 2 - 5 } & Konsep I Konsep II & Konsep I & Konsep II \\
\hline Tampilan Desain & 3,09 & 3,60 & 3,30 & 3,50 \\
Kepraktisan & 3,44 & 3,29 & 3,50 & 3,20 \\
Kualitas & 3,47 & 3,24 & 3,60 & 3,20 \\
Kenyamanan & 3,04 & 3,49 & 3,60 & 3,30 \\
Kebersihan & 3,42 & 3,29 & 3,80 & 3,40 \\
\hline
\end{tabular}

Tabel 6. Performansi dan value prototipe konsep

\begin{tabular}{lcccc}
\hline \multirow{2}{*}{ Keterangan } & \multicolumn{2}{c}{ Performansi } & \multicolumn{2}{c}{ Value } \\
\cline { 2 - 5 } & Konsep I Konsep II & Konsep I & Konsep II \\
\hline Pengunjung & 331,02 & 337,48 & $66,2 \times 10^{-5}$ & $48,42 \times 10^{-5}$ \\
Pemilik Rumah & 355,96 & 329,07 & $71,19 \times 10^{-5}$ & $47,01 \times 10^{-5}$ \\
Makan & & & & \\
\hline
\end{tabular}

\section{Simpulan}

Atribut kebutuhan pengunjung terhadap meja dan kursi makan portabel adalah tampilan desain meja, kepraktisan, kualitas, kenyamanan dan kebersihan. 
Atribut kebutuhan pemilik rumah makan adalah tampilan desain, kepraktisan, kualitas, kenyamanan, kerapian dan kebersihan.

Desain meja dan kursi makan portabel yang dibutuhkan pengunjung dan pemilik rumah makan merupakan desain yang menggunakan konsep folding dan combination. Konsep bentuk combination/modular dapat memudahkan penataan dan menyesuaikan kebutuhan. Konsep ukuran anthropometri harus memperhatikan dimensi tubuh ratarata pengunjung. Pemilihan warna natural di sesuaikan dengan konsep alami yang dapat menyatu dengan lingkungan cemara udang.

Dua desain yang dihasilkan dalam penelitian ini merupakan hasil dari berbagai alternatif pengembangan. Desain meja dan kursi makan portabel ini merupakan desain yang menggunakan konsep folding dan combination Prototipe Konsep I dengan desain kapasitas satu orang namun dapat dibongkar pasang untuk menyesuaikan kapasitasnya. Bahan kerangka dan permukaan kayu dengan bentuk permukaan meja dan alas duduk persegi panjang, tanpa motif/ hiasan dan busa tambahan, dan warna natural merupakan konsep terpilih dengan value yang didapatkan dari pengunjung $66,2 \times 10^{-5}$ dan dari pemilik $71,19 \times 10^{-5}$

\section{Ucapan Terima Kasih}

Penulis mengucapkan terima kasih kepada Program Hibah Kompetisi-Institusi (PHK-I) Tema C Unit Fakultas Teknologi Pertanian Universitas Gadjah Mada Tahun 2011 dalam dukungan finansial terhadap penelitian ini dan Badan Perencanaan Pengembangan (BAPPEDA) Kabupaten Bantul, Provinsi Daerah Istimewa Yogyakarta dalam dukungan terhadap fasilitasi pelaksanaan penelitian.

\section{Daftar Pustaka}

1. Arikunto, S., Prosedur Penelitian: Suatu Pendekatan Praktek, Rineka Cipta, Jakarta, 1996.

2. Barnes, C. J., Childs, T. H. C., Henson, B., and Southee, C. H., Surface Finish and Touch: A Case Study in a New Human Factors Tribology, Wear, 247 (7-8), 2004, pp. 740-750.

3. Deng, Y., and Kao, Y. P., The Development of Musical Selection Plan based on Kansei Similarity, National Chiao Tung University, Institute of Applied Art, 2003.

4. Fandeli, C., Perencanaan Kepariwisataan Alam, Fakultas Kehutanan Universitas Gadjah Mada, Yogyakarta, 2002.

5. Galt Furniture, The Complete Furniture Range For Playgroups, Nurseries and Primary Schools, Tanpa kota, 1999.
6. Madyana, A. M., Analisis Perancangan Kerja Jilid 1, Penerbit Universitas Atma Jaya, Yogyakarta, 1996.

7. Martadi, Konsep Desain Bangku dan Kursi Sekolah Dasar di Surabaya, Dimensi Interior, 4(2), 2006, pp.72-79.

8. Nagamachi, M., Kansei Engineering: A New Ergonomic Consumer Oriented Technology for Product Development, International Journal of Industrial Ergonomics, 15, 1995, pp.3-11.

9. Nagamachi, M., Kansei Engineering as a Powerful Consumer Oriented Technology for Product Development, Applied Ergonomics, 33, 2002, pp. 289-294.

10. Nurmianto, E., Ergonomi: Konsep Dasar dan Aplikasinya, Guna Widya, Surabaya, 2003.

11. Palgunadi, B., Desain Produk: Aspek-aspek Desain, Penerbit ITB, Bandung, 2008.

12. Rouse, Design for Success, Wiley, New York, 1991.

13. Sari, N. P., Pengembangan Produk Nata De Cassava dalam Kemasan Menggunakan Metode Value Engineering berdasarkan Kansei Word, Skripsi Program Studi Teknologi Industri Pertanian, Universitas Gadjah Mada, 2011.

14. Stevenson, M. G., Principles of Ergonomics. Center for Safety Science-University of NSW, Australia, 1989.

15. Suma'mur, Hiperkes Keselamatan Kerja dan Ergonomi, Jakarta: BP. Dharma Bakti, 1994.

16. Suwarno, Perbaikan Lingkungan Kerja pada Pengrajin Ukiran Kelongsong Peluru dengan Menyesuaikan Tinggi Meja Kerja di Desa Kamasan, Klungkung, Jurnal Permukiman Natah, 3 (2), 2005, pp. 62-101.

17. Tarwaka, Bakri, S. H. A., and Sudiadjeng, L., Ergonomi untuk Keselamatan, Kesehatan Kerja, dan Produktifitas, Uniba press, Surakarta, 2004.

18. Ulrich, K. T., and Eppinger, Perancangan dan Pengembangan Produk (Penerjemah Nora Azmi dan Iveline Anne Marie), Penerbit Salemba Teknika dan Irwin McGraw-Hill, Jakarta, Indonesia, 2001.

19. Ushada, M., and Murase, H., Design of Customizable Greening Material using Swarm Modelling, Biosystem Engineering, 104(2), 2009, pp. 169-183.

20. Ushada, M., Wicaksono, A., and Murase, H., Design of Moss Greening Material for Merapi Disaster Prone Area using Kansei Engineering, Engineering in Agriculture, Environment and Food, in Press 2012. (http://mama.agr.okayamau.ac.jp/AABEA/).

21. Ushada, M., Sari, N. P., and Supartono, W., Pengembangan Nata De Cassava Siap Saji dalam Kemasan Menggunakan Pendekatan 
Kansei Engineering, Proceeding Seminar Asosiasi Profesi Teknologi Agroindustri (APTA) Tahun 2011, Indonesian Institute of Life Cycle Assessment on Food Products and Recent Progress in Agroindustry, ISSN No: 978-97918918-1-3, 2011.
22. Wignjosoebroto, S., Prinsip-prinsip Perancangan Berbasiskan Dimensi Tubuh (Antropometri) dan Perancangan Stasiun Kerja, Lokakarya IV: Methods Engineering: Adaptasi ISO/TC159 (Ergonomics) dalam Standar Nasional Indonesia (SNI), Bandung, 17-19 Oktober 2000. 